\title{
Role of the aromatic bridge on radical ions formation during reduction of diphosphaalkenes $\dagger \ddagger$
}

\author{
Manuel Lejeune, ${ }^{a}$ Philippe Grosshans, ${ }^{a}$ Théo Berclaz, ${ }^{a}$ Helena Sidorenkova, ${ }^{a}$ \\ Céline Besnard, ${ }^{b}$ Phil Pattison ${ }^{c d}$ and Michel Geoffroy ${ }^{* a}$
}

Received (in Montpellier, France) 9th April 2011, Accepted 13th July 2011

DOI: $10.1039 / \mathrm{c} \operatorname{lnj20314b}$

Two molecules containing two phenylphosphaalkene moieties linked by an anthracene (1) or by a naphthalene (2) ring have been synthesized and their crystal structures have been determined. While electrochemical measurements show that these two systems are easily reduced, EPR spectra indicate that, at room temperature, the electronic structures of the two reduction compounds $\mathbf{1}^{\mathbf{0}^{-}}$ and $\mathbf{2}^{-\boldsymbol{}}$ are quite different. In $\mathbf{1}^{\bullet-}$, in good accordance with DFT predictions, the unpaired electron is delocalized on the full molecule while in $\mathbf{2}^{\mathbf{-}}$ it is confined on a single phosphaalkene moiety. This difference is attributed to the short distance between the two phenylphosphaalkene groups in $\mathbf{2}^{\mathbf{*}}$ which hinders their reorientation after addition of an electron. The role of this motion is consistent with the fact that two additional paramagnetic species are detected at $145 \mathrm{~K}$ : the dianion $\mathbf{2}^{\mathbf{2}-}$ characterized by a rather small exchange coupling constant and the radical monoanion $2^{* \bullet-}$ resulting from the formation of a one electron P-P bond. These two species are probably reaction intermediates which can lead to the formation of biphosphane.

\section{Introduction}

Molecular and supramolecular systems containing several redox switches have received much attention in recent years because of their potential applications in modern material science and microelectronics. ${ }^{1}$ They play, for example, an important role in the design of nanoelectromechanical devices ${ }^{2}$ and of molecular magnets. ${ }^{3}$ In most of these systems, the nature of the bridge between two redox centers is often determining for the response of the compound to external stimuli. For example, the shuttling of a crown ether along a redox-active rotaxane is affected by the flexibility of the bridge between viologen recognition sites. ${ }^{4}$ In compounds containing

${ }^{a}$ Department of Physical Chemistry, University of Geneva, 30 Quai Ernest Ansermet, CH-1211 Geneva, Switzerland. E-mail: Michel.Geoffroy@unige.ch

${ }^{b}$ Laboratory of Crystallography, University of Geneva, 24 quai Ernest-Ansermet, CH-1211 Geneva, Switzerland. E-mail: Celine.Besnard@unige.ch

${ }^{c}$ Laboratory of Crystallography, Ecole Polytechnique Fédérale de

Lausanne, CH 1015 Lausanne, Switzerland

${ }^{d}$ Swiss Norwegian Beamline, European Synchrotron Radiation

Facility, Grenoble, France

$\dagger$ To the memory of Pascal Le Floch (1958-2010).

$\ddagger$ Electronic supplementary information (ESI) available: Syntheses and spectroscopic characterization of $\mathbf{1}^{\prime \prime}, \mathbf{1}^{\prime}, \mathbf{2}^{\prime \prime}, \mathbf{2}^{\prime}, \mathbf{3}, \mathbf{4}^{\prime}, \mathbf{4}$; geometrical parameters from the crystal structures of $\mathbf{1}$ and $\mathbf{2}$; geometrical parameters, energies and coupling constants for DFT optimized structures of $\mathbf{1}^{\mathbf{\bullet}}$; experimental and simulated EPR spectra, cyclic voltammograms for 3 . CCDC reference numbers 815021 and 815022 . For ESI and crystallographic data in CIF or other electronic format see DOI: 10.1039/ clnj20314b two TTF moieties linked by an organic bridge, the ability of the system to give rise to mixed valence species after oxidation depends on the nature of the spacer. ${ }^{5}$

There is currently much interest in compounds containing diarylethene switches bonded through delocalized bridges. ${ }^{6}$ In diarylethene-capped sexithiophene wires, electrochemical ring cyclization and cycloreversion are influenced by the participation of the thiophene linker in the frontier orbitals of the resulting paramagnetic dication. ${ }^{7}$

The purpose of the present work is to assess the role of the bridge in the reduction mechanism of a system containing two

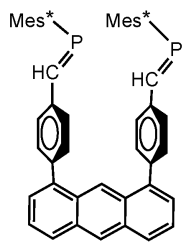

1

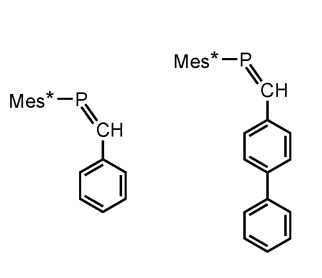

5

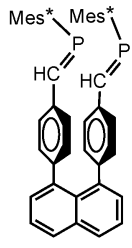

2

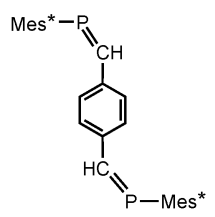

7

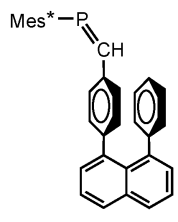

4

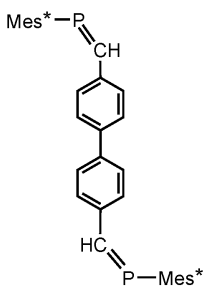

8 
phosphaalkene groups. $\mathrm{P}=\mathrm{C}$ containing compounds are well-known to accept easily an additional electron in their $\pi^{*}$ orbitals $^{8}$ and sterically encumbered diphosphaalkenes have already been reported as potential multiredox-active molecular switches. ${ }^{9}$ We report the syntheses and crystal structures of $\mathbf{1}$ and $\mathbf{2}$ (Chart 1) which only differ by the size of the aromatic bridge. By means of electrochemical and EPR measurements the paramagnetic reaction intermediates formed during reduction of these two diphosphaalkenes are identified. In order to facilitate the interpretation of these results in terms of the radical structure, the hyperfine coupling constants observed after reduction of $\mathbf{1}$ and $\mathbf{2}$ are compared with those of the four monophosphaalkenes $\mathbf{3}, \mathbf{4}, \mathbf{5},{ }^{8 a} \mathbf{6}^{10}$ and of the two diphosphaalkenes 7 and $\mathbf{8}^{10}$ (Chart 1).

\section{Results}

\subsection{Syntheses}

The syntheses of the new mono- or diphosphaalkenes are outlined in Scheme 1.

The dialdehydes 4,4'-(anthracene-1,8-diyl)dibenzaldehyde $\left(\mathbf{1}^{\prime}\right)$ and 4,4'-(naphthalene-1,8-diyl)dibenzaldehyde $\left(\mathbf{2}^{\prime}\right)$ were obtained by hydrolysis of the corresponding acetal $\mathbf{1}^{\prime \prime}$ and $\mathbf{2}^{\prime \prime}$, prepared via Negishi cross-coupling ${ }^{11}$ between 2-(4-bromophenyl)-1,3-dioxane and the corresponding diiodide molecule.

Bisphosphaalkenes $\mathbf{1}$ and $\mathbf{2}$ were then synthesized using the one pot procedure developed by Yoshifuji et al. ${ }^{12}$ After a first lithiation reaction, Mes*PHLi was converted into its silyl derivative by reaction with ${ }^{t} \mathrm{BuMe} \mathrm{SiCl}_{2}$ at low temperature. The deprotonation of $\mathrm{Mes}{ }^{*} \mathrm{PH}\left(\mathrm{SiMe}_{2}{ }^{\mathrm{t}} \mathrm{Bu}\right)$ by the second lithiation step afforded the silylphosphide Mes* $\mathrm{P}\left(\mathrm{SiMe}_{2}{ }^{t} \mathrm{Bu}\right) \mathrm{Li}$ which could then react at $-78^{\circ} \mathrm{C}$ with the appropriate aldehyde $\left(\mathbf{1}^{\prime}\right.$ or $\mathbf{2}^{\prime}$ ), thus leading to the formation of compounds 1 and 2 in $48 \%$ and $78 \%$ yield, respectively. It should be noted that these reactions were carried out in the dark in order to favour the $E$-configuration around the $\mathrm{P}=\mathrm{C}$ bond. The stereospecificity of the reaction is, besides, confirmed by ${ }^{31} \mathrm{P}$ NMR studies which showed a unique doublet with a $J_{\mathrm{PH}}$ coupling constant lower than $30 \mathrm{~Hz}\left(J_{\mathrm{PH}}(\mathbf{1})=25.2 \mathrm{~Hz} ; J_{\mathrm{PH}}(\mathbf{2})=\right.$ $25.1 \mathrm{~Hz})$, corresponding to the $(E, E)$-isomer. ${ }^{13}$ No $(Z, Z)-$ and $(Z, E)$-isomers were observed in the reaction mixtures.

The new phosphaalkenes $(E)-\mathbf{3}$ and $(E)-\mathbf{4}$ were synthesized according to the same procedure described above. Synthesis of 4 required the preparation of 1-(4-formylphenyl)-8-phenyl naphthalene $\mathbf{4}^{\prime}$ which was obtained via double Suzuki crosscouplings ${ }^{14}$ between 1,8-diiodonaphthalene and the boronic acid derivatives.

\subsection{Crystal structures of 1 and 2}

For 1, fine platelets were formed which diffracted very weakly. Measurements were carried out at the Swiss-Norwegian Beamline at the European Synchrotron Radiation Facility. For 2, the measurements were performed using Mo-radiation. Details of the refinement are reported in ESI. $\ddagger$

Compound $\mathbf{1}$ crystallizes in the triclinic system, space group $P \overline{1}$; compound $\mathbf{2}$ crystallizes in the monoclinic system, space group $P 2_{1} / n$. As reported in ESI, $\ddagger$ for both compounds, the two Mes* $\mathrm{P}=\mathrm{C}(\mathrm{H})-\mathrm{C}_{6} \mathrm{H}_{5}$ moieties exhibit the geometrical characteristics reported for this type of phosphaalkene: ${ }^{15}$ the $\mathrm{CPC}(\mathrm{H}) \mathrm{C}$ groups are practically planar, and are oriented perpendicular to the benzene ring of Mes* (Ph3a or Ph3b hereafter, see Fig. 1), the $\mathrm{PC}(\mathrm{H}) \mathrm{C}$ planes make an angle of $\sim 30^{\circ}$

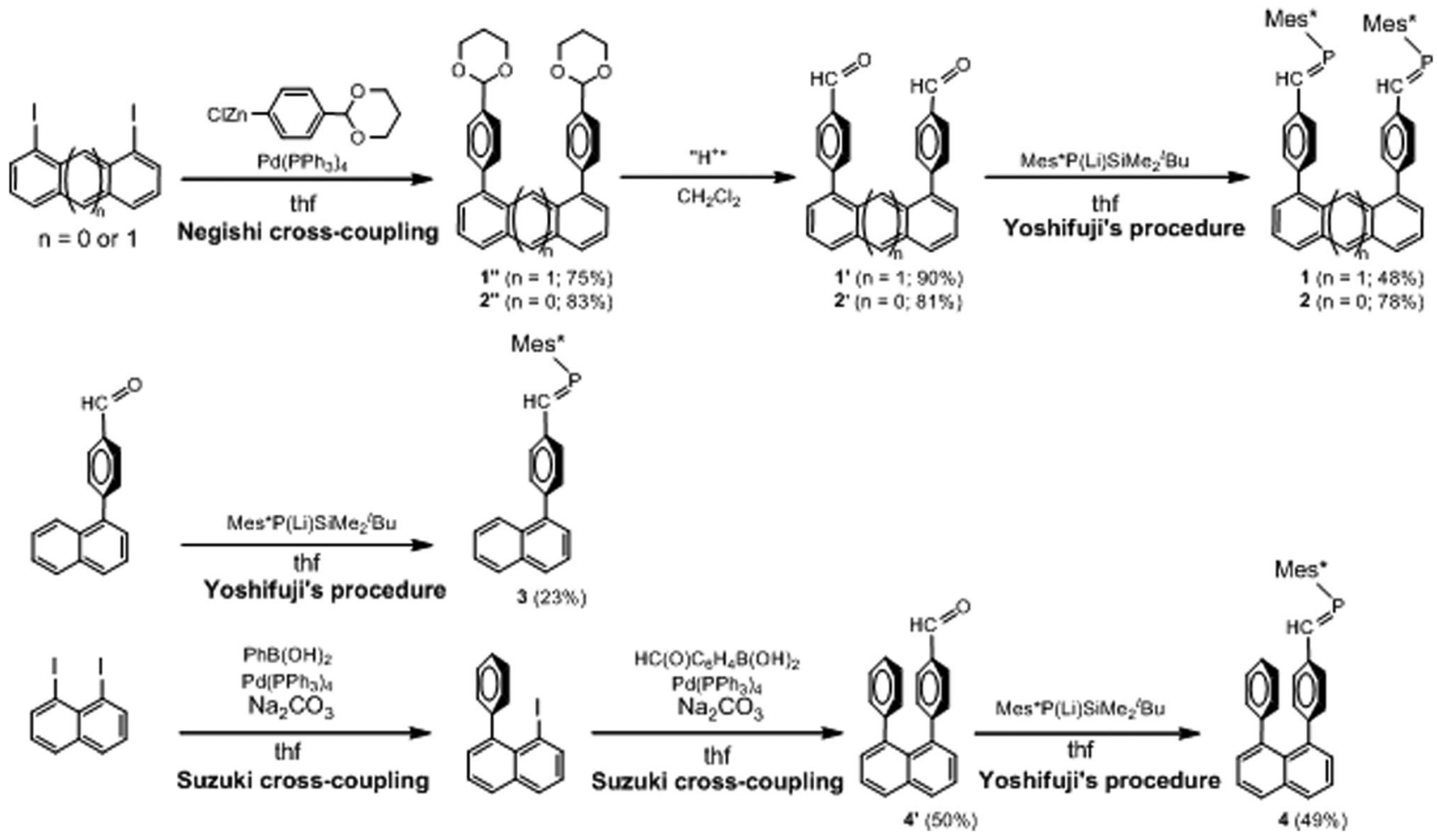

Scheme 1 

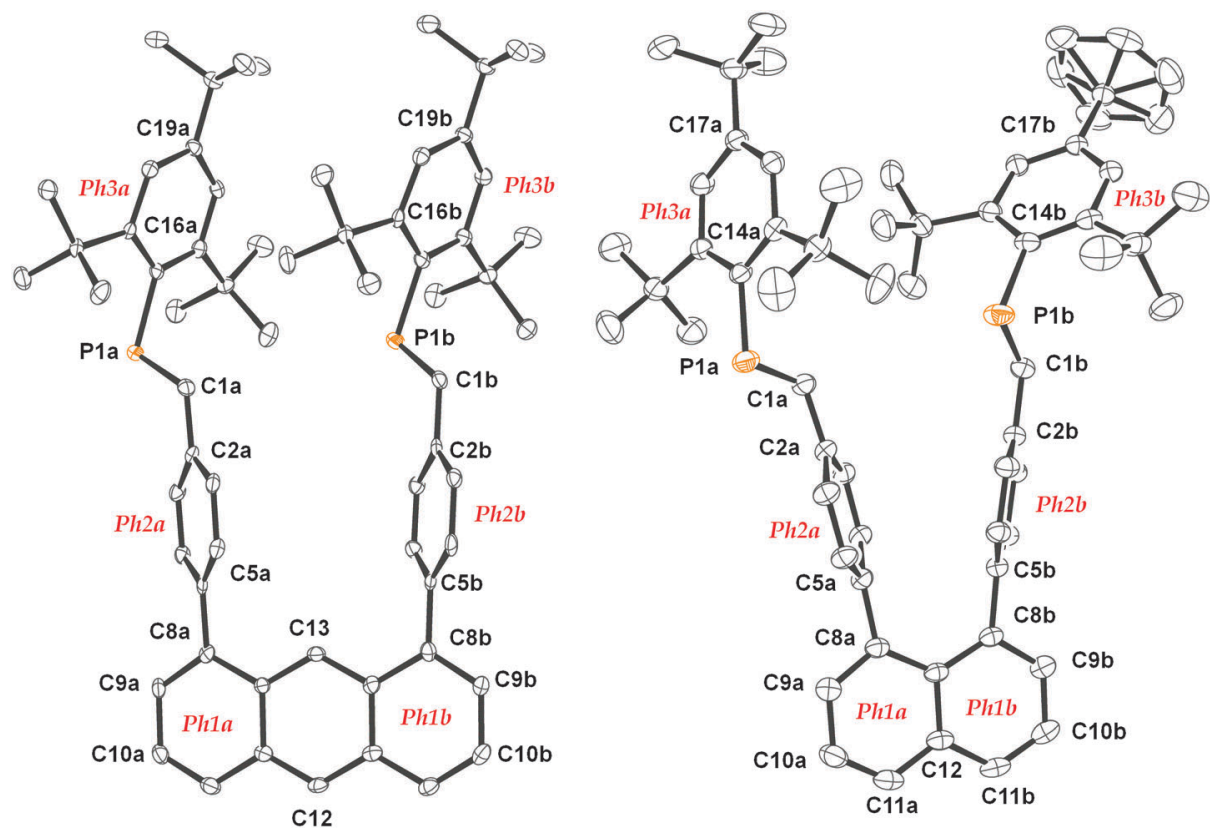

Fig. 1 Crystal structures of $\mathbf{1}$ and $\mathbf{2}$ with numbering of the aromatic rings. Hydrogen atoms are omitted for clarity. Thermal ellipsoids are shown at $50 \%$ probability for $\mathbf{1}$ and $25 \%$ probability for $\mathbf{2}$ (Diffraction measurement was performed at $100 \mathrm{~K}$ for $\mathbf{1}$ and at $293 \mathrm{~K}$ for $\mathbf{2}$, which accounts for the different degrees of thermal motion.).

with the adjacent phenyl rings (Ph2a or Ph2b hereafter, see Fig. 1) linked to the anthracene (or naphthalene) ring.

The main differences between the conformations of $\mathbf{1}$ and $\mathbf{2}$ result from the steric interactions between the phenyl rings $P h 2 a$ and $P h 2 b$ : the distance between the centroids of these two phenyl rings is equal to $5.30 \AA$ in $\mathbf{1}$ and only $3.66 \AA$ in $\mathbf{2}$. In 1 the constraints are, of course, less pronounced than in the naphthalene containing system: while the $\xi$ interplane angles (Ph1a, Ph2a) and (Ph1b, Ph2b) are equal to $52.6^{\circ}$ and $47.9^{\circ}$ in $\mathbf{A}_{\mathbf{1}}$, they reach $61.8^{\circ}$ and $65.0^{\circ}$ in $\mathbf{2}$. Strong hindrance between the two encumbered $P h 2 \mathrm{C}(\mathrm{H}) \mathrm{P}=\mathrm{Mes}^{*}$ groups is also revealed by the fact that the angle between the Cla..C8a and $\mathrm{C} 1 \mathrm{~b} \cdots \mathrm{C} 8 \mathrm{~b}$ directions is more pronounced in $2\left(23.4^{\circ}\right)$ than in $1\left(7.5^{\circ}\right)$. Moreover, the distances between the two phosphaalkene bonds are appreciably shorter in 2 (distance $\mathrm{P} 1 \mathrm{a} \cdots \mathrm{P} 1 \mathrm{~b}=5.620 \AA$, distance $\mathrm{Cla} \cdots \mathrm{C} 1 \mathrm{~b}=4.957 \AA$ ) than in 1 (distance $\mathrm{P} 1 \mathrm{a} \cdots \mathrm{P} 1 \mathrm{~b}=5.844 \AA$, distance $\mathrm{Cla} \cdots \mathrm{C} 1 \mathrm{~b}=$ $5.643 \AA)$.

\subsection{Cyclic voltammetry}

Three reduction waves are observed on the voltammogram obtained with 1 (Fig. 2a). The two first waves are quasi-reversible and their parameters are given in Table 1 . The voltammogram obtained with 2 (Fig. 2b) is more complex; a first broad reduction wave is partially overlapped by a second irreversible wave which precludes a precise determination of $E_{\mathrm{pc}}$. The voltammogram obtained with $\mathbf{4}$ is shown in Fig. 3. The electrochemical parameters of these compounds are given in Table 1, together with those of $\mathbf{3}$ whose voltammogram is shown in ESI. $\ddagger$ For the sake of comparison the values previously reported for the monophosphaalkenes $\mathbf{5}$ and $\mathbf{6}$ and the diphosphaalkenes $\mathbf{7}$ and $\mathbf{8}$ are also shown in Table 1.
Table 1 Reduction potentials ${ }^{a}$ for some mono- and diphosphaalkenes

\begin{tabular}{lllll}
\hline Compound & $E_{\mathrm{pc}} / \mathrm{V}$ & $E_{\mathrm{pa}} / \mathrm{V}$ & $E_{\mathrm{pc}}-E_{\mathrm{pa}} / \mathrm{V}$ & $E_{\mathrm{red}} / \mathrm{V}$ \\
\hline $\mathbf{1}$ & -1.82 & -1.72 & 0.10 & -1.77 \\
$\mathbf{2}$ & -2.00 & -1.90 & 0.10 & -1.95 \\
$\mathbf{3}$ & & -1.89 & & \\
$\mathbf{4}$ & -1.97 & -1.84 & 0.13 & -1.91 \\
$\mathbf{5}^{8 a}$ & -2.01 & -1.89 & 0.12 & -1.95 \\
$\mathbf{6}^{10}$ & -2.15 & -1.82 & 0.33 & -1.99 \\
$\mathbf{7}^{10}$ & -1.93 & -1.80 & 0.13 & -1.64 \\
$\mathbf{8}^{10}$ & -1.69 & -1.59 & 0.10 & -1.74 \\
${ }^{a} \mathrm{~V}$ vs. SCE. & -1.78 & -1.69 & 0.09 & \\
\hline
\end{tabular}

\subsection{DFT calculations}

The fact that our attempts to get an optimized structure of $\mathbf{2}^{\bullet-}$ with no imaginary frequency remained unsuccessful prevented us from using DFT for assessing the reduction mechanism of $\mathbf{2}$.

2.4.1. Radical anion $\mathbf{1}^{\bullet-}$. Due to hindered rotation around the $\mathrm{Cla}-\mathrm{P} 1 \mathrm{a}$ and $\mathrm{C} 1 \mathrm{~b}-\mathrm{P} 1 \mathrm{~b}$ bonds as well as around the $\mathrm{C} 2 \mathrm{a}-\mathrm{Cla}$ and $\mathrm{C} 2 \mathrm{~b}-\mathrm{Clb}$ bonds, the radical anion $\mathbf{1}^{\mathbf{0}^{-}}$is expected to adopt 6 main conformations. Rotations around the carbon-phosphorus bonds lead to the $E$ and $Z$ isomers, while rotations around the carbon-carbon bonds lead to isomers called $C$ ( $c i s$, both phosphorus atoms on the same side of the anthracene plane) or $T$ (trans, a phosphorus atom on each side of the anthracene plane). The structures of the six rotamers $C_{E E}, C_{E Z}, C_{Z Z}, T_{E E}, T_{E Z}, T_{Z Z}$ have been optimized, conformations of $C_{Z E}$ and $T_{Z Z}$ are represented in Fig. 4; all the energies are comprised in a $2.35 \mathrm{kcal} \mathrm{mol}^{-1}$ range; $T_{E E}$ is found as being the most stable rotamer. These energies together with the geometry parameters are given in ESI. $\ddagger$ 

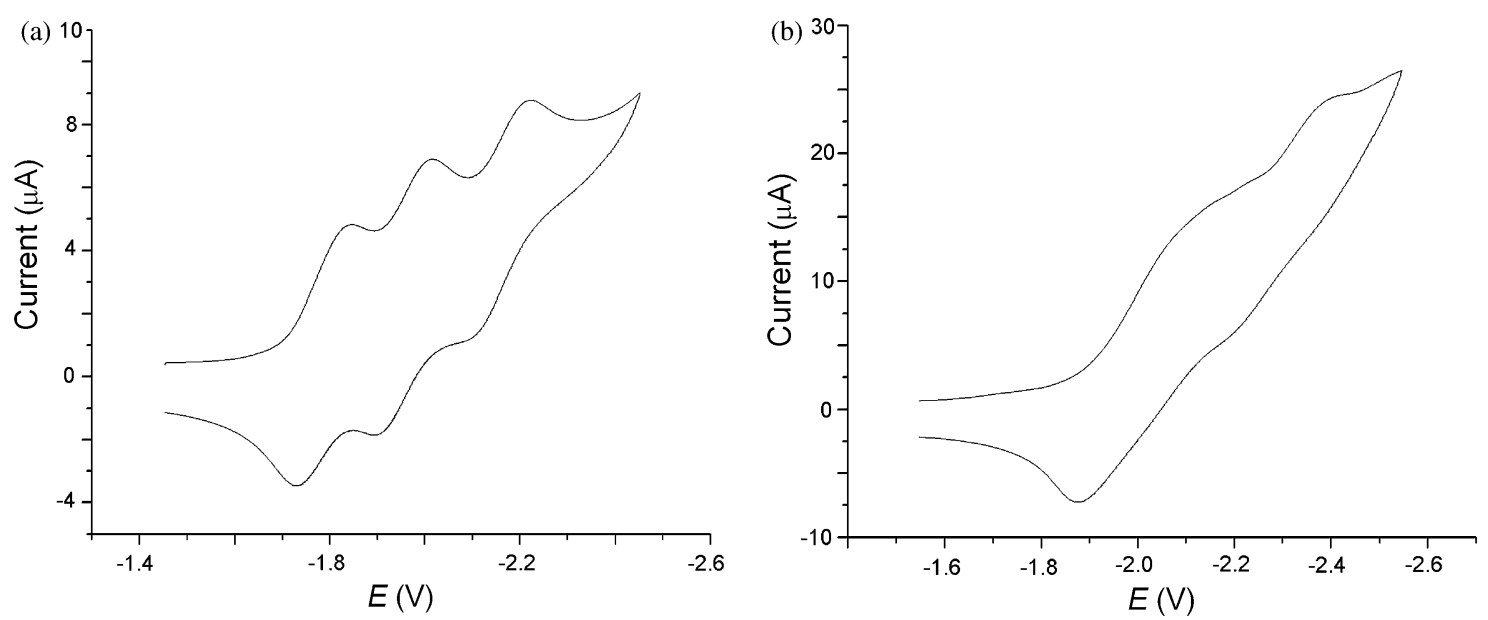

Fig. 2 Cyclic voltammograms of diphosphaalkenes 1 (a) and 2 (b) recorded on a Pt working electrode at $100 \mathrm{mV} \mathrm{s}$ in THF with 0.1 M $\mathrm{Bu}_{4} \mathrm{NPF}_{6}$, ref. SCE.

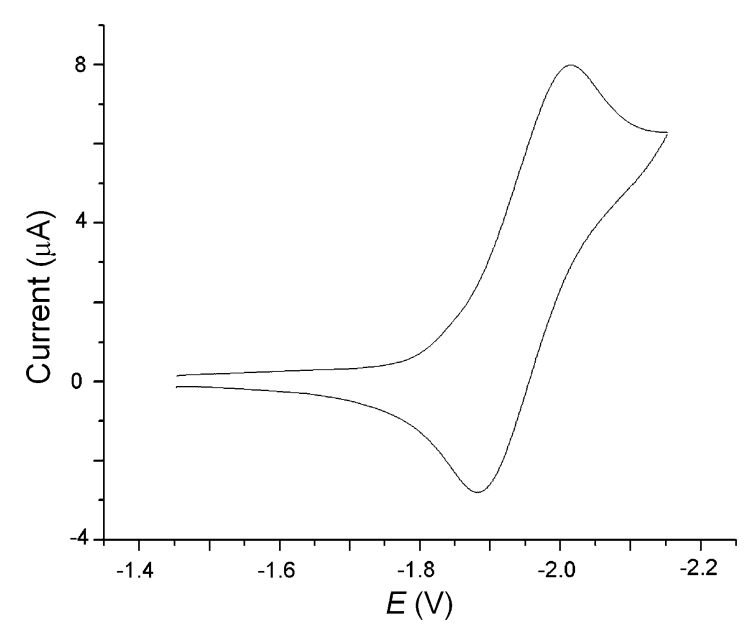

Fig. 3 Voltammogram obtained with the monophosphaalkene 4.

It can be remarked that, in the crystal, both neutral compounds $\mathbf{1}$ and $\mathbf{2}$ adopt a $C_{E E}$ conformation.

For all rotamers the benzene rings of the Mes* groups remain oriented perpendicular to the adjacent CPC moieties and the $P h 2 a$ and $P h 2 b$ rings are almost coplanar with the adjacent CCP planes (dihedral angle less than $5^{\circ}$ instead of $30^{\circ}$ for the crystal structure of neutral 1). The $P h 2 a$ and $P h 2 b$ rings make an angle of $\sim 43^{\circ}$ with the anthracene plane (instead of $52.6^{\circ}$ and $47.9^{\circ}$ in the crystal structure of neutral 1). The distances between the two phosphorus atoms range from $7.518 \AA$ (for $C_{\mathrm{ZE}}$ ) to $9.429 \AA$ (for $T_{\mathrm{EE}}$ ), and are considerably longer than the distance measured for the neutral compound (5.84 ̊).

The ${ }^{31} \mathrm{P}$ and ${ }^{1} \mathrm{H}$ isotropic hyperfine coupling constants have been calculated; as expected they are sensitive to the conformation of the radical anion and are given in ESI $\ddagger$ for the six rotamers. In Table 2 we report only the couplings larger than $1.0 \mathrm{G}$; it is clear that several protons $\left(\mathrm{H} 11 \mathrm{a}, \mathrm{H} 11 \mathrm{~b}, \mathrm{H}_{12}\right.$, $\mathrm{H} 9 \mathrm{a}$ and $\mathrm{H} 9 \mathrm{~b}$, Chart 2) are likely to participate in the observed ${ }^{1} \mathrm{H}$ hyperfine pattern $\left(a\left({ }^{1} \mathrm{H}\right)=2.5 \mathrm{G}\right.$, vide infra $)$.

\subsection{EPR study}

2.5.1. Anthracene-containing diphosphaalkene 1. At room temperature, reduction of a THF solution of $\mathbf{1}$ with $\mathrm{Na}$ naphthalenide leads to the EPR spectrum shown in Fig. 5a. The 1-2-1 triplet structure is attributed to hyperfine interaction with two ${ }^{31} \mathrm{P}$ nuclei; an additional substructure, probably due to protons, is characterized by splittings of $\sim 2.5 \mathrm{G}$. The low

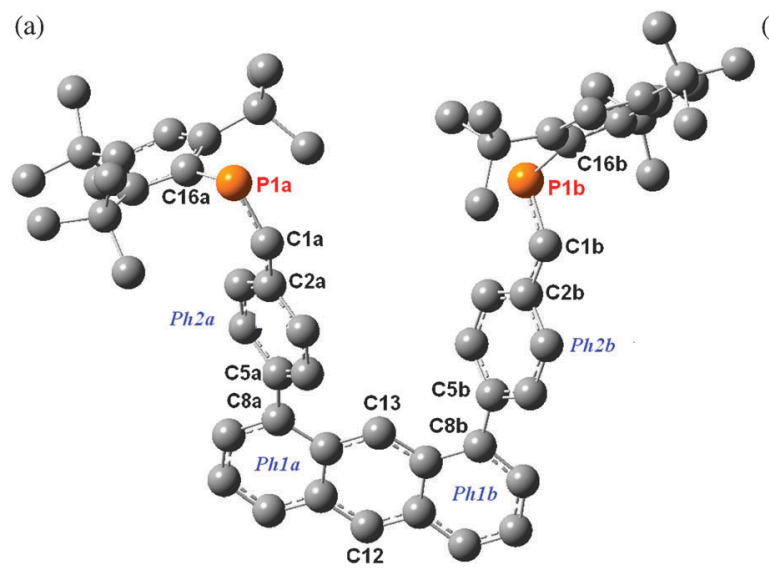

(b)

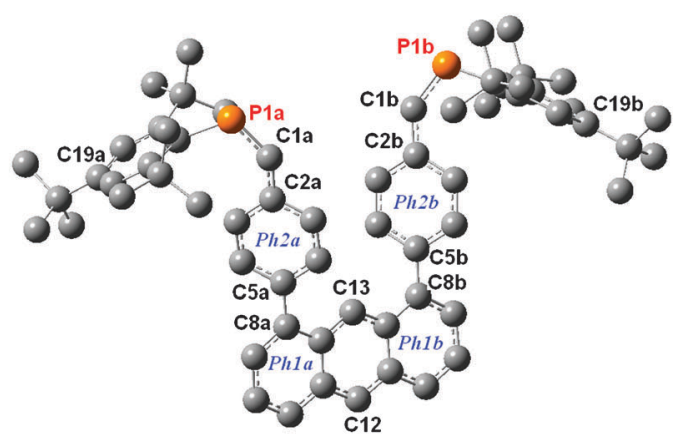

Fig. 4 Optimized structures for the conformations $C_{Z E}$ and $T_{Z Z}$ of $\mathbf{1}^{\bullet-}$. 
Table 2 Ranges of the calculated isotropic hyperfine splitting constants (Gauss) for the six rotamers of $\mathbf{1}^{\bullet-}$

\begin{tabular}{lcccccc}
\hline Nuclei & ${ }^{31} \mathrm{P} 1 \mathrm{a},{ }^{31} \mathrm{P} 1 \mathrm{~b}$ & ${ }^{1} \mathrm{H} 11 \mathrm{a},{ }^{1} \mathrm{H} 11 \mathrm{~b}$ & ${ }^{1} \mathrm{H} 9 \mathrm{a},{ }^{1} \mathrm{H} 9 \mathrm{~b}$ & ${ }^{1} \mathrm{H}_{12}$ & ${ }^{1} \mathrm{H} 1 \mathrm{a},{ }^{1} \mathrm{H} 1 \mathrm{~b}$ & ${ }^{1} \mathrm{H} 13$ \\
\hline Coupling range & {$[9.4$ to 13.1$]$} & {$[-2.9$ to -3.1$]$} & {$[-2.2$ to -2.4$]$} & {$[-3.1$ to -3.5$]$} & {$[-0.6$ to -1.2$]$} & {$[-0.9$ to -1.5$]$} \\
\hline
\end{tabular}

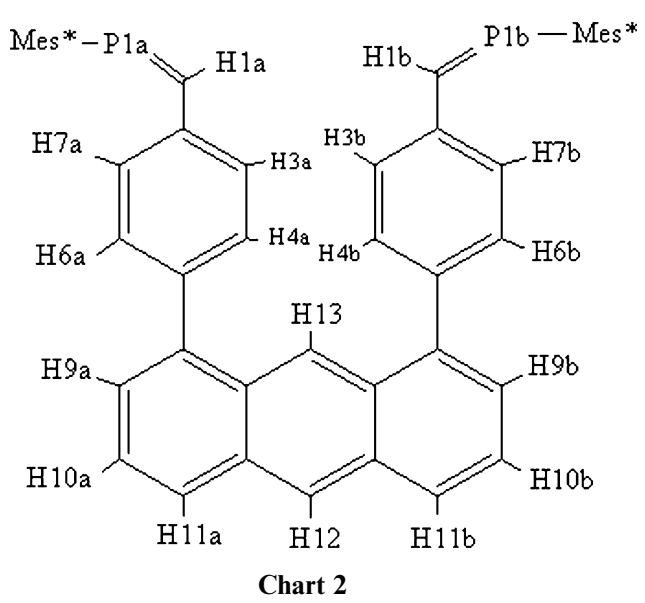

field pattern clearly shows that this hyperfine substructure is composed of 7 transitions.

Since DFT calculations on $\mathbf{1}^{\mathbf{-}}$ indicate that this radical anion can adopt several conformations of similar energy, it is rather difficult to accurately analyse the observed hyperfine structure. Nevertheless, as shown in Fig. 5a, overlaps of the lines hardly occur on the lateral parts of the spectrum obtained after reaction with a small amount of reduction agent. The low field part of the spectrum was therefore used for the determination of the coupling constants. As shown by spectrum simulation (see ESI $\ddagger$ ), the observed pattern (1-6-15-20-15-6-1) can be explained by assuming the coexistence of two nonexchanging structures characterized by a coupling with two ${ }^{31} \mathrm{P}$ nuclei $\left(a\left({ }^{31} \mathrm{P}\right)=16.0 \mathrm{G}\right.$ for isomer $1,13.5 \mathrm{G}$ for isomer 2$)$ and with five equivalent protons $\left(a\left({ }^{1} \mathrm{H}\right) \approx 2.5 \mathrm{G}\right.$ for isomer 1 and isomer 2). However, as shown in ESI, $\ddagger$ the experimental spectrum can also be simulated by assuming that a rapid exchange between several rotamers leads to an averaged coupling $a\left({ }^{1} \mathrm{H}\right) \approx 2.5 \mathrm{G}$ with six protons and of $14.9 \mathrm{G}$ with two ${ }^{31} \mathrm{P}$ nuclei. Decreasing temperature causes a broadening of the lines but never modifies the relative intensities inside the proton structure; this observation seems more in accordance with the second hypothesis. Moreover, a rapid exchange between the various rotamers is consistent with DFT results which indicate that energy differences between these rotamers are very low. At $110 \mathrm{~K}$, only a very broad line is detected (Fig. 5b). Simulation of the frozen solution spectrum is given in ESI. +

The hyperfine pattern observed after electrochemical reduction of a solution of $\mathbf{1}$ in THF is quite similar to the structure observed in Fig. 5a; however, the line-shape appears to be altered by dynamics effects and perhaps by interaction with the electrode (spectrum shown in ESI $\ddagger$ ).

\subsubsection{Naphthalene-containing diphosphaalkenes}

Compound 2. At $295 \mathrm{~K}$, the spectrum obtained by electrochemical reduction of $\mathbf{2}$ in solution in THF exhibits two lines of similar intensity and separated by $50.4 \mathrm{G}$ (Fig. 6a). This EPR response disappears when the voltage is switched off. The solution turns to blue when electrolyzed. Rapid cooling $(130 \mathrm{~K})$ of the paramagnetic solution hinders molecular motion and, as shown in Fig. 6b, reveals the anisotropic components of the EPR tensors. This spectrum is simulated by using the $g$ and ${ }^{31} \mathrm{P}$ hyperfine tensors, of axial symmetry, reported in Table 3 (see ESI $\ddagger$ ). The resulting isotropic hyperfine splitting constant $(48.3 \mathrm{G})$ agrees with the value measured in the liquid phase $(50.4 \mathrm{G})$. The same spectra are observed by chemical reduction at $295 \mathrm{~K}$ with $\mathrm{Na}$ naphthalenide, the colour of the resulting solution is dark blue.

When drops of a solution of $\mathrm{Na}$ naphthalenide are added, at $243 \mathrm{~K}$, to a solution of 2 in THF the colour of the solution becomes violet; then, if temperature is increased or if the tube is stirred the colour turns from violet to blue. The EPR spectrum obtained with the violet solution exhibits three types of lines (Fig. 7): two signals L1, L2 separated by $50 \mathrm{G}$, a central line marked $\mathrm{M}$ and two lines, marked $\mathrm{T} 1$ and $\mathrm{T} 2$, separated by $20 \mathrm{G}$. Increasing temperature causes a rapid disappearance of the T1 and T2 lines but not of the lines L1, L2 and M. When Na naphthalenide is added to this solution at
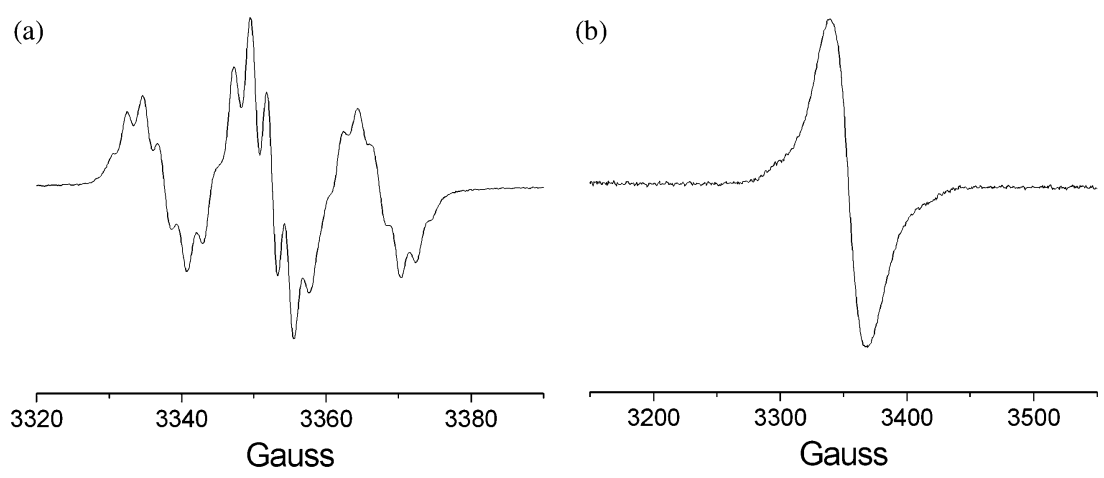

Fig. 5 EPR spectra obtained after reduction at RT of a solution of 1 with Na naphthalenide. (a) Spectrum recorded at $295 \mathrm{~K}$, (b) spectrum recorded at $110 \mathrm{~K}$ (peak-to-peak linewidth $=30 \mathrm{G}$ ). 


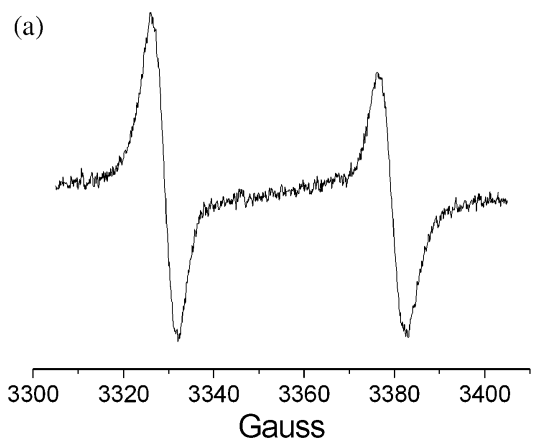

(b)

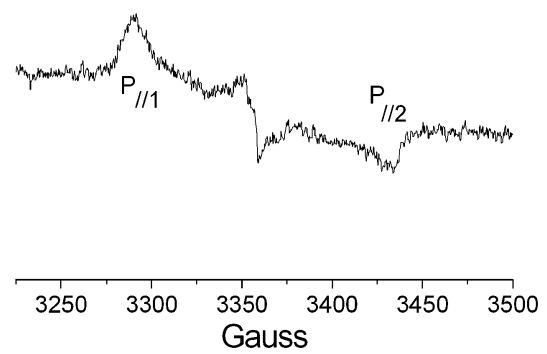

Fig. 6 EPR spectra obtained after electrochemical reduction of a solution of $\mathbf{2}$ in THF (a) spectrum recorded at $295 \mathrm{~K}$, (b) spectrum recorded at $130 \mathrm{~K}$.

Table 3 EPR parameters obtained after reduction of phosphaalkenes containing a naphthalene group 2, 3, and 4

\begin{tabular}{|c|c|c|c|c|c|c|c|c|c|}
\hline \multirow[b]{2}{*}{ Reduced solution } & \multicolumn{2}{|c|}{ Liquid solution } & \multicolumn{7}{|c|}{ Frozen solution } \\
\hline & $g$ & $a\left({ }^{31} \mathrm{P}\right)$ & $g_{\perp}$ & $g_{\|}$ & ${ }^{31} \mathrm{P}-T_{\perp(\mathrm{G})}$ & ${ }^{31} \mathrm{P}-T_{\|}$ & ${ }^{31} \mathrm{P}-\tau_{\perp}$ & ${ }^{31} \mathrm{P}-\tau_{\|}$ & $a\left({ }^{31} \mathrm{P}\right)$ \\
\hline 2 & 2.0075 & 50.4 & 2.0085 & 2.0055 & 3.0 & 142.0 & -46.8 & 93.7 & 48.3 \\
\hline 3 & 2.0078 & 54.0 & 2.0087 & 2.0060 & 3.0 & 156.0 & -51.5 & 103.0 & 53.0 \\
\hline 4 & 2.0076 & 50.4 & 2.0085 & 2.0057 & 3.0 & 148.0 & -48.8 & 97.7 & 50.3 \\
\hline
\end{tabular}

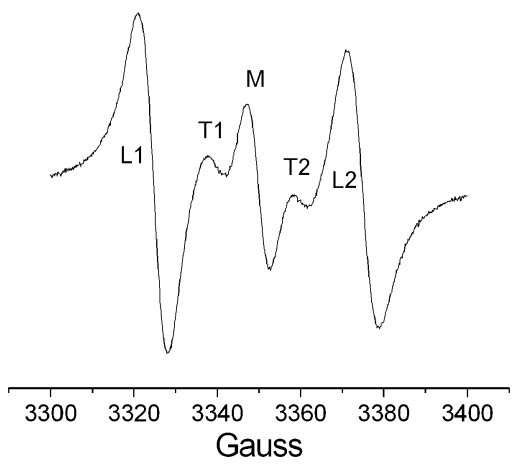

Fig. 7 EPR spectrum obtained at $243 \mathrm{~K}$ after reaction, at the same temperature, of a solution of $\mathbf{2}$ in THF with Na naphthalenide.

$295 \mathrm{~K}$, only the two L lines remain present on the spectrum. The frozen solution spectrum obtained with the violet solutions not only exhibits two lines similar to $P_{\| 1}$ and $P_{\| 2}$ as shown in Fig. 6b, but also a broad and intense central pattern.

Compounds 3 and 4 . Both electrochemical reduction (295 K) and chemical reduction ( $\mathrm{Na}$ naphthalenide, $285 \mathrm{~K}$ ) of a solution of 3 in THF lead to a two-line EPR spectrum characterized by $g=2.0077$ and ${ }^{31} \mathrm{P}$ hyperfine splitting constant equal to $54 \mathrm{G}$. The frozen solution spectrum, recorded at $110 \mathrm{~K}$, after chemical reduction is readily simulated by using the parameters reported in Table 3. Electrochemical and chemical reductions of $\mathbf{4}$ lead to the same observations as for 3. Both reduction compounds have very similar EPR parameters. Decomposition of the ${ }^{31} \mathrm{P}$ hyperfine tensor $\left(T\left({ }^{31} \mathrm{P}\right)\right)$ into its isotropic $\left(a\left({ }^{31} \mathrm{P}\right)\right)$ and anisotropic $\left(\tau\left({ }^{31} \mathrm{P}\right)\right)$ components is shown in Table 3, together with the $g$ anisotropy.

\section{Discussion}

\subsection{Reduction potentials of mono- and diphosphaalkenes}

The potentials of the first reduction wave of compounds containing a single phosphaalkene group linked to a phenyl ring (e.g. 5, ${ }^{8 a} \mathbf{6},{ }^{10} \mathbf{4}$, Table 1) range from -1.87 to $-1.99 \mathrm{~V}$. As shown by the reduction potentials measured for $7(-1.64 \mathrm{~V})$ and $\mathbf{8}(-1.74 \mathrm{~V})$, the presence of a second $*$ Mes $-\mathrm{P}=\mathrm{CH}$ group causes a decrease of at least $0.13 \mathrm{~V}$ of the absolute values of $E_{\text {red }}$. Consistent with a diphosphaalkene, $\mathbf{1}$ is reduced at $-1.77 \mathrm{~V}$. For $\mathbf{2}$, however, the behaviour seems to be quite different. Addition of a second Mes*-P $=\mathrm{CH}$ moiety to $\mathbf{4}$ does not affect the value of $E_{\mathrm{pa}}$ and the shape of the voltammogram does not indicate a decrease of the absolute value of $E_{\text {red }}$ when passing from $\mathbf{4}$ to $\mathbf{2}$. The electrochemical behaviour of $\mathbf{2}$ seems therefore to be more related to a monophosphaalkene than to a diphosphaalkene; we will now check if this property is corroborated by EPR.

\subsection{Spin delocalisation in mono- and diphosphaalkene radical anions}

In the "classical" phosphaalkene monoradical anion $\mathbf{5}^{\mathbf{\bullet}}, 8 a$ the unpaired electron is mainly confined in the $\mathrm{P}=\mathrm{C} \pi^{*}$ bond, with ${ }^{a}{ }^{31} \mathrm{P}$ hyperfine interaction $\left(a\left({ }^{31} \mathrm{P}\right)=54 \mathrm{G}, \tau_{\|}\left({ }^{31} \mathrm{P}\right)=108 \mathrm{G}\right)$ consistent with a phosphorus spin density around $45 \%$. Increasing the size of the aromatic moiety linked to the $\mathrm{Ph}$ ring in $\mathrm{Mes} * \mathrm{P}=\mathrm{C}(\mathrm{H}) \mathrm{Ph}$ hardly affects the spin delocalization: in $\mathbf{6}^{\boldsymbol{0}^{-10}}$ and $\mathbf{3}^{\circ-}$, the ${ }^{31} \mathrm{P}$ isotropic hyperfine splitting constant remains close to $54 \mathrm{G}$; moreover, in $4^{\mathbf{0}^{-}}$, the presence of a second phenyl ring bound to the naphthalene has no effect on the phosphorus spin density. As already reported for $\mathbf{7}^{-}$and $\mathbf{8}^{\mathbf{-}},{ }^{10}$ the presence of a second phosphaalkene group causes 
a marked diminution of the ${ }^{31} \mathrm{P}$ coupling $\left(a\left({ }^{31} \mathrm{P}\right)=43 \mathrm{G}\right.$ and $34 \mathrm{G}$, respectively). In these two radical anions, the unpaired electron is mainly shared by the two phosphaalkene groups, a residual part of the spin remains on the bridge and depends upon the nature of this bridge. In the next paragraph we examine how this spin sharing between the two phosphaalkene groups operates for radical anions formed from $\mathbf{1}$ and $\mathbf{2}$.

As shown by cyclic voltammetry (Fig. 2a), the first and second reduction waves of $\mathbf{1}$ are clearly separated and their quasi-reversible character suggests that the radical monoanion can be observed by EPR in solution. Indeed, independently of the model used for the simulation of the spectrum, the experimental coupling constants are close to the values predicted by DFT for $\mathbf{1}^{\bullet-}$. The fact that the calculated $A_{\text {iso }}\left({ }^{31} \mathrm{P}\right)$ values are slightly smaller than the experimental constants has often been mentioned for other phosphorus radical ions. ${ }^{10,16}$

The hyperfine interaction $\left(a\left({ }^{31} \mathrm{P}\right) \approx 13 \mathrm{G}\right)$ with two ${ }^{31} \mathrm{P}$ nuclei demonstrates that, as for $\mathbf{7}^{-}$and $\mathbf{8}^{\bullet-}$, in $\mathbf{1}^{\bullet-}$ the unpaired electron is delocalized on the two phosphaalkene groups; nevertheless, couplings with protons of the anthracene ring indicate that an appreciable part of the spin also lies on this part of the molecule. Clearly, the dihedral angle between anthracene and the adjacent phenylene rings is sufficiently small to allow electron communication between the two phosphaalkene groups. These experimental results are consistent with the SOMO shown, for example, for the $T_{E E}$ conformation of $\mathbf{1}^{\bullet-}$ (Fig. 8) and are confirmed by the calculated spin densities: $\rho=0.20$ on each $\mathrm{P}=\mathrm{C}$ bond, $\rho=0.10$ on each $\mathrm{Ph} 2$ ring, $\rho=0.40$ on the anthracene bridge and zero on the Mes* groups. It can be remarked that such a delocalization of the unpaired electron is quite suitable for the trapping of a $\mathrm{Na}^{+}$ion inside the "cavity"; the formation of this type of complex is perhaps important for the stabilization of some conformations.

The situation is quite different when the anthracene moiety is replaced by a naphthalene ring. Only a coupling with a single ${ }^{31} \mathrm{P}$ nucleus is observed on the spectrum recorded at room temperature after reduction of $\mathbf{2}$ and no proton hyperfine interaction is detected. This ${ }^{31} \mathrm{P}$ isotropic hyperfine splitting constant $(\sim 50 \mathrm{G})$ is almost equal to that observed after reduction of $\mathbf{5}$ and the anisotropic coupling constants confirm a large participation of a phosphorus p-orbital to the SOMO. Two hypotheses are consistent with this observation: (1) formation of a biradical with an exchange coupling constant $J$ equal to zero; this species would result from the capture of an

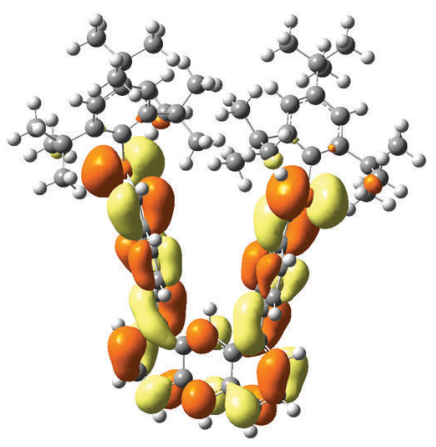

Fig. 8 Representation of the SOMO for the $T_{E E}$ conformation of $1^{\bullet-}$.

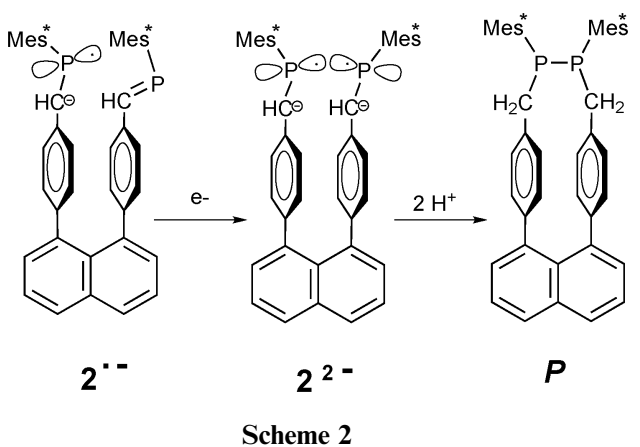

electron by each phosphaalkene moiety and (2) only one of the two phosphaalkene groups is reduced, the additional electron remains localized on this group.

The fact that the frozen solution spectrum obtained with $\mathbf{2}$ corresponds to that of a single monophosphaalkene radical anion, without any distortion or modification due to dipolar interaction with the neighbouring reduced $(\mathrm{P}=\mathrm{C})$ group is less compatible with the first hypothesis. In accord with the second hypothesis, cyclic voltammetry shows that an irreversible reduction process, likely associated with the formation of $\mathbf{2}^{\mathbf{2}}$, occurs very close to the first reduction wave (quasi-reversible, formation of $\mathbf{2}^{\mathbf{\bullet}}$ ). This suggests that during the relaxation process which follows the electron capture by one of the two phosphaalkene groups (say PA), the steric interactions between the two $\left(\mathrm{C}_{6} \mathrm{H}_{4}\right)-\mathrm{C}=\mathrm{P}-\mathrm{Mes}$ * chains considerably slow down the required conformational changes. The large value of the initial torsion angle $\xi$ probably hinders spin delocalisation and contributes to an increase of the lifetime of the $\mathrm{PA}^{\bullet-}$ configuration and explains why a single ${ }^{31} \mathrm{P}$ coupling contributes to the hyperfine pattern. At room temperature, as soon as the second phosphaalkene group (say PB) is reduced, the system becomes diamagnetic, probably due to the formation of a P-P bond and a subsequent protonation of the phosphaalkene carbons. Such a mechanism is illustrated in Scheme 2 which uses the limit mesomeric form $-{ }^{-} \mathrm{C}(\mathrm{H})-\cdot P$ for the phosphaalkene monoradical anion.

\subsection{Reaction intermediates during reduction of 2 at low temperature}

In contrast with $\mathbf{1}$ which leads to a single type of EPR spectrum, the nature of the signals detected with $\mathbf{2}$ is dependent upon the reaction temperature. We will now examine to what extent the second hypothesis mentioned above for the structure of $\mathbf{2}^{-\boldsymbol{}}$ is consistent with experiments performed at $245 \mathrm{~K}$. We have previously shown, with a two phosphinine containing macrocycle, that when two unsaturated carbonphosphorus bonds are maintained close to each other with an orientation allowing overlap of the phosphorus $\mathrm{p}_{\pi}$ orbitals, a reduction process can lead to the formation of a one-electron $\mathrm{P}-\mathrm{P}$ bond (Chart 3). ${ }^{17}$ In the resulting radical anion, the $a\left({ }^{31} \mathrm{P}\right)$ value is small $(<2.5 \mathrm{G})$ and, likely, this coupling could remain unresolved in a less rigid system.

As shown by the crystal structure, in 2 the initial P...P distance is only $5.6 \AA$ and the angle between the two CPC planes is only $18^{\circ}$; likely, a rather small change of conformation, 


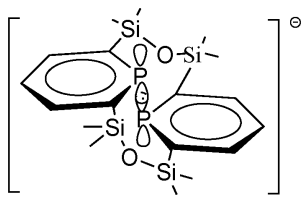

Chart 3

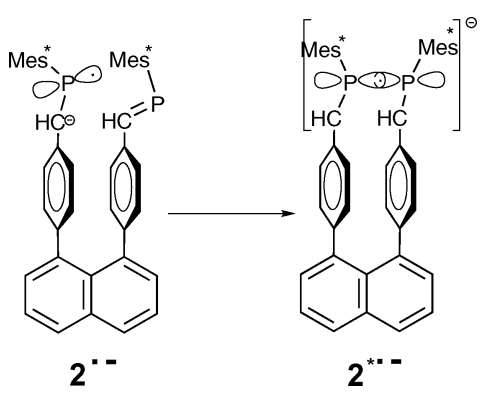

Scheme 3

subsequent to an electron capture, can lead to the formation of a one-electron P-P bond (species $\mathbf{2}^{*-\boldsymbol{}}$ ) as shown in Scheme 3.

The central line M (Fig. 7), observed at $245 \mathrm{~K}$ by chemical reduction of $\mathbf{2}$, agrees with this mechanism which gives rise to the radical $2^{* \bullet-}$. It should be remarked, however, that this central line could also result from a hopping of the unpaired electron between the two phosphaalkene sites; in this hypothesis the phosphorus hyperfine splitting constant equal to $25 \mathrm{G}$ (half the value found for $[-\mathrm{P}=\mathrm{C}]^{\bullet-}$ ) would lead to a 1-2-1 pattern with the two external lines hidden by the two lines of $\mathbf{2}^{\mathbf{0}}$. Nevertheless, we favour the formation of $\mathbf{2}^{* \bullet-}$ which is a direct precursor of the final reduction compound $\mathbf{P}$.

At $245 \mathrm{~K}$, two additional signals, marked T1 and T2 (Fig. 7) and separated by $20 \mathrm{G}$, are also detected. They are reminiscent of unidentified signals already mentioned in a previous study on systems containing two phosphaalkene groups. ${ }^{10}$ In the present study, using the X-Sophe program, ${ }^{18}$ we have simulated the spectra of a biradical whose exchange coupling value $J$ is close to the hyperfine couplings $\left(A_{\text {iso }}\right)$ with two ${ }^{31} \mathrm{P}$ nuclei. Using $A_{\text {iso }}$ values equal to $47 \times 10^{-4} \mathrm{~cm}^{-1}$ (49.8 if expressed in Gauss) and a $J$ value equal to $50 \times 10^{-4} \mathrm{~cm}^{-1}$ leads to the spectrum shown in Fig. 9.

Addition of this spectrum to those simulated for $\mathbf{2}^{\bullet-}$ and $2^{* \bullet-}$ leads to the spectrum shown in Fig. 10 which is a very satisfactory simulation of the experimental spectrum shown in Fig. 7. The relative abundances of the corresponding

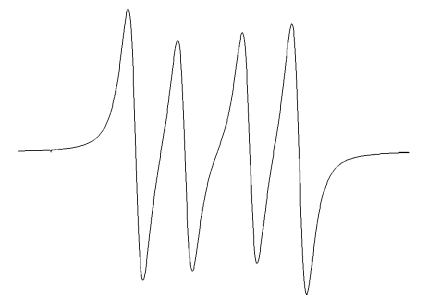

$\begin{array}{llllllll}3280 & 3300 & 3320 & 3340 & 3360 & 3380 & 3400 & 3420\end{array}$ Gauss

Fig. 9 Simulation of the spectrum due to the biradical $\mathbf{2}^{\mathbf{2}-}$ by assuming $J=50 \times 10^{-4} \mathrm{~cm}^{-1}$.

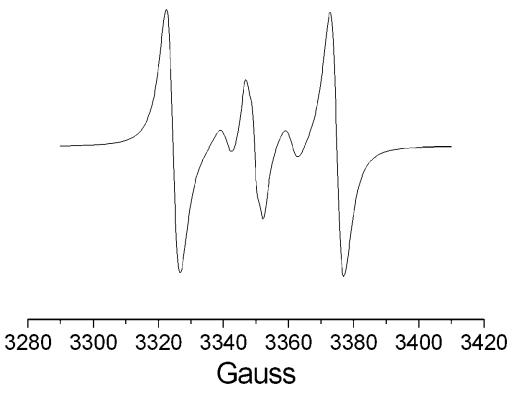

Fig. 10 Simulation of the spectrum expected for a solution containing a mixture of $\mathbf{2}^{\bullet-}(64 \%), \mathbf{2}^{*--}(18 \%)$ and $\mathbf{2}^{\mathbf{2}}(18 \%)$.

species- $18 \%, 64 \%, 18 \%$, respectively-were estimated by optimizing the weighting coefficients (see ESI $\ddagger$ ).

The $a\left({ }^{31} \mathrm{P}\right)$ values of the biradical responsible for the signals T1 and T2 (Fig. 7) are close to the constant measured for the monoradicals $\mathbf{C}_{\mathbf{1}}{ }^{--}$and $\mathbf{B}_{\mathbf{1}}{ }^{--}$and indicate that these signals can be assigned to the dianion $\mathbf{2}^{\mathbf{2}-}$.

Working at low temperature increases therefore the life times of two paramagnetic intermediates, $\mathbf{2}^{* \mathbf{\bullet}^{-}}$and $\mathbf{2}^{\mathbf{2}-}$, which can lead, after protonation, to the diamagnetic reduction compound $\mathbf{P}$.

\section{Conclusion}

The chemical behaviour of a system containing two identical reduction centers does not only result from the nature of these centers but is also determined by both their relative orientation and the orientation of the bridging group. In this context, all the factors which can affect the conformation of the molecule can therefore be determining for the evolution of the reduction process. This is specially the case for fluxional systems containing cumbersome groups; as shown with $\mathbf{1}$ and $\mathbf{2}$, replacement of a naphthalene group by anthracene considerably modifies the communicability between the two phosphaalkene moieties, determines the structure of the monoradical anion and influences the stability of the biradical dianion. The present work shows that all these effects affect the spin delocalisation in systems containing two redox sites bonded through delocalized bridges and that the nature of these bridges can be crucial for the control of electronic devices containing multiple switching units.

\section{Experimental}

\subsection{General}

All syntheses were performed in Schlenk-type flasks under dry nitrogen. Solvents were dried by conventional methods and distilled immediately prior to use. Tetrabutylammonium hexafluorophosphate $\left(\mathrm{TBAPF}_{6}\right)$ was recrystallized twice from ethanol $/ \mathrm{H}_{2} \mathrm{O}(1: 1)$ and dried under vacuum. Phenylboronic acid and 4-formylphenylboronic acid were purchased from Aldrich and used as received. Routine ${ }^{1} \mathrm{H},{ }^{13} \mathrm{C}\left\{{ }^{1} \mathrm{H}\right\}$ and ${ }^{31} \mathrm{P}$ spectra were recorded at $25^{\circ} \mathrm{C}$ with FT Bruker instruments (Bruker AMX-300 or Bruker DRX-500 MHz). ${ }^{1} \mathrm{H}$ NMR spectra were referenced to residual protiated solvents $(7.26 \mathrm{ppm}$ for $\left.\mathrm{CDCl}_{3}\right),{ }^{13} \mathrm{C}$ chemical shifts are reported relative 
to deuterated solvents $\left(77.0 \mathrm{ppm}\right.$ for $\left.\mathrm{CDCl}_{3}\right)$, and the ${ }^{31} \mathrm{P}$ NMR data are given relative to external $\mathrm{H}_{3} \mathrm{PO}_{4}$. Multiplicity is indicated as follows: $s$ (singlet), $d$ (doublet), $t$ (triplet), $\mathrm{m}$ (multiplet), dd (doublet of doublet). In the ${ }^{13} \mathrm{C}$ NMR data $\mathrm{C}_{\mathrm{q}}$ denotes a quaternary carbon atom and $\mathrm{C}^{\prime} \mathrm{s}$ indicates a secondary carbon atom. The infra-red spectra were measured on a Perkin Elmer Spectrum 100 FT-IR spectrometer with ATR sampling accessory. Electron impact (EI) mass spectra were obtained using a Varian $\mathrm{CH}-4$ instrument and Electrospray ionization (ESI) mass spectra were recorded on a Finnigan SSQ 7000 spectrometer at the Laboratory of Mass Spectroscopy of the University of Geneva. Melting points (mp) were measured on a Büchi 510 melting point apparatus and were uncorrected

\subsection{Syntheses}

$\mathrm{Pd}\left(\mathrm{PPh}_{3}\right)_{4},{ }^{19} 1,8$-diiodonaphthalene, ${ }^{20} 1,9$-diiodoanthracene, ${ }^{21}$ 2-(4-bromophenyl)-1,3-dioxane ${ }^{22}$ and 1-(4-formylphenyl)naphthalene ${ }^{23}$ were prepared according to methods reported in the literature. Syntheses and spectroscopic characterizations of the following compounds are given in ESIł: 1,8-bis(4-(1,3dioxan-2-yl)phenylanthracene (1' $\left.\mathbf{1}^{\prime \prime}\right), 4,4^{\prime}$-(anthracene-1,8-diyl)dibenzaldehyde $\left(\mathbf{1}^{\prime}\right)$, 1,8-bis(4-(1,3-dioxan-2-yl)phenyl)naphthalene $\left(\mathbf{2}^{\prime \prime}\right), \quad 4,4^{\prime}$-(naphthalene-1,8-diyl)dibenzaldehyde $\quad\left(\mathbf{2}^{\prime}\right), \quad(E)$-1-[4(2-(2,4,6-tri-tert-butylphenyl)phosphaethenyl)phenyl]naphthalene (3), 1-iodo-8-phenylnaphthalene, 4-(8-phenylnaphthalen-1-yl)benzaldehyde $\left(4^{\prime}\right)$, and (E)-1-[4-(2-(2,4,6-tri-tert-butylphenyl)phosphaethenyl)phenyl]-8-phenyl-naphthalene (4)

5.2.1. 1,8-Bis((4-(E)-(2,4,6-tri-tert-butylphenyl)phosphaethenyl) phenyl)anthracene (1). A solution of ${ }^{n} \mathrm{BuLi}$ in hexane (1.6 M, $0.75 \mathrm{~mL}, 1.20 \mathrm{mmol})$ was added to a solution of 2,4,6-tri-tertbutylphosphine $(0.281 \mathrm{~g}, 1.01 \mathrm{mmol})$ in THF $(20 \mathrm{~mL})$ at $-78^{\circ} \mathrm{C}$ in the dark. After $15 \mathrm{~min}$, the solution of ${ }^{t} \mathrm{BuMe} 2 \mathrm{SiCl}(0.197 \mathrm{~g}$, $1.31 \mathrm{mmol})$ in THF $(10 \mathrm{~mL})$ was added dropwise at $0{ }^{\circ} \mathrm{C}$ and the resulting mixture was warmed up to room temperature for $45 \mathrm{~min}$. ${ }^{n} \mathrm{BuLi}(1.6 \mathrm{M}, 0.75 \mathrm{~mL}, 1.20 \mathrm{mmol})$ was added again at $0{ }^{\circ} \mathrm{C}$ to the pale yellow reaction mixture. After $15 \mathrm{~min}$ at room temperature, the solution was cooled to $-78{ }^{\circ} \mathrm{C}$ and $\mathbf{1}^{\prime}(0.150 \mathrm{~g}, 0.38 \mathrm{mmol})$ in THF $(10 \mathrm{~mL})$ was added dropwise. Then, the mixture was warmed up to room temperature and the solution was stirred $1 \mathrm{~h}$ in the dark. The solvent was evaporated under reduced pressure and the residue was subjected to column chromatography on silica gel in the dark (hexane then hexane $\left./ \mathrm{CH}_{2} \mathrm{Cl}_{2}(9: 1, \mathrm{v} / \mathrm{v})\right)$ to give 1 as a pale yellow powder $\left(\mathrm{SiO}_{2}, R_{\mathrm{f}}=0.3\right.$, hexane $/ \mathrm{CH}_{2} \mathrm{Cl}_{2}$ (9:1, v/v)). Yield: $48 \%, 0.170 \mathrm{~g}, 0.19 \mathrm{mmol} . \mathrm{mp}=242-243{ }^{\circ} \mathrm{C}$. ${ }^{1} \mathrm{H}$ NMR $\left(300 \mathrm{MHz}, \mathrm{CDCl}_{3}, 298 \mathrm{~K}\right): \delta 9.05(\mathrm{~s}, 1 \mathrm{H}, \mathrm{H}$ of anthracene), 8.57 (s, 1H, $\mathrm{H}$ of anthracene), 8.20 (d $2 \mathrm{H}$, $\left.\mathrm{C}(\mathrm{H})=\mathrm{P},{ }^{2} J_{\mathrm{PC}}=25.3 \mathrm{~Hz}\right), 8.04(\mathrm{~d}, 2 \mathrm{H}, \mathrm{H}$ of anthracene, $\left.{ }^{3} J_{\mathrm{HH}}=8.5 \mathrm{~Hz}\right), 7.62\left(\mathrm{dd}, 4 \mathrm{H}, o-\mathrm{H}\right.$ of $\mathrm{C}_{6} \mathrm{H}_{4},{ }^{3} J_{\mathrm{HH}}=8.4$, $\left.{ }^{4} J_{\mathrm{PH}}=2.5 \mathrm{~Hz}\right), 7.57-7.52\left(\mathrm{~m}, 6 \mathrm{H}, m-\mathrm{H}\right.$ of $\mathrm{C}_{6} \mathrm{H}_{4}$ and $\mathrm{H}$ of anthracene), 7.47-7.44 (m, 6H, $\mathrm{H}$ of anthracene and $m-\mathrm{H}$ of Mes*), 1.51 (s, 36H, o- $\left.{ }^{t} \mathrm{Bu}\right), 1.36$ (s, 18H, p- $\left.{ }^{t} \mathrm{Bu}\right) .{ }^{13} \mathrm{C}\left\{{ }^{1} \mathrm{H}\right\}$ NMR (75.46 MHz, $\left.\mathrm{CDCl}_{3}, 298 \mathrm{~K}\right): \delta 175.28(\mathrm{~d}, \mathrm{C}(\mathrm{H})=\mathrm{P}$, $\left.{ }^{1} J_{\mathrm{PC}}=34.1 \mathrm{~Hz}\right), 154.08\left(\mathrm{~s}, o-\mathrm{Mes}^{*}(\mathrm{C})\right), 149.65\left(\mathrm{~s}, p-\mathrm{Mes}^{*}(\mathrm{C})\right)$, $140.28\left(\mathrm{~d}, i-\mathrm{C}\right.$ of $\left.\mathrm{C}_{6} \mathrm{H}_{4},{ }^{2} J_{\mathrm{PC}}=7.8 \mathrm{~Hz}\right), 139.98-139.43\left(3 \mathrm{~s}, \mathrm{C}_{\mathrm{q}}\right.$ of anthracene), $138.92\left(\mathrm{~d}, i-\mathrm{C}\right.$ of $\left.\mathrm{Mes}^{*},{ }^{1} J_{\mathrm{PC}}=54.1 \mathrm{~Hz}\right), 132.01$ $\left(\mathrm{s}, \mathrm{C}_{\mathrm{q}}\right.$ of $\left.\mathrm{C}_{6} \mathrm{H}_{4}\right), 130.43\left(\mathrm{~d}, m-\mathrm{C}\right.$ of $\left.\mathrm{C}_{6} \mathrm{H}_{4},{ }^{4} \mathrm{~J}_{\mathrm{PC}}=1.9 \mathrm{~Hz}\right), 129.65$ (s, $\mathrm{C}_{\mathrm{q}}$ of anthracene), 127.91-126.97 (3s, $\mathrm{C}^{\prime} \mathrm{s}$ of anthracene), $125.73\left(\mathrm{~d}, o-\mathrm{C}\right.$ of $\left.\left.\mathrm{C}_{6} \mathrm{H}_{4}\right),{ }^{3} J_{\mathrm{PH}}=21.9 \mathrm{~Hz}\right), 123.37\left(\mathrm{~s}, \mathrm{C}^{\prime} \mathrm{s}\right.$ of anthracene), 121.82 (s, $m-\mathrm{C}$ of $\left.\mathrm{Mes}^{*}\right), 38.32$ (s, o- $\left.C\left(\mathrm{CH}_{3}\right)_{3}\right)$, $35.03\left(\mathrm{~s}, m-C\left(\mathrm{CH}_{3}\right)_{3}\right), 33.97\left(\mathrm{~d}, o-\mathrm{C}\left(\mathrm{CH}_{3}\right)_{3},{ }^{4} J_{\mathrm{P}-\mathrm{C}}=6.4 \mathrm{~Hz}\right)$, 31.46 (s, $\left.m-\mathrm{C}\left(\mathrm{CH}_{3}\right)_{3}\right) .{ }^{31} \mathrm{P}$ NMR (121.5 MHz $\left.\mathrm{CDCl}_{3}, 298 \mathrm{~K}\right): \delta$ $260.95\left(\mathrm{~d}, \mathrm{C}(\mathrm{H})=\mathrm{P},{ }^{2} J_{\mathrm{PH}}=25.2 \mathrm{~Hz}\right)$. EI-MS: $m / z(\%) 905$ (24) $[\mathrm{M}]^{+}, 793$ (6) $\left[\mathrm{M}-2^{t} \mathrm{Bu}\right]^{+}, 631$ (39) $\left[\mathrm{M}-\mathrm{PMes}{ }^{*}\right]^{+}, 357$ (46) $[\mathrm{M}-2 \mathrm{PMes}]^{+}$.

5.2.2. 1,8-Bis((4-(E)-(2,4,6-tri-tert-butylphenyl)phosphaethenyl) phenyl)naphthalene (2). A solution of ${ }^{n} \mathrm{BuLi}$ in hexane $(1.6 \mathrm{M}$, $0.48 \mathrm{~mL}, 0.77 \mathrm{mmol})$ was added to a solution of 2,4,6-tri-tertbutylphosphine $(0.215 \mathrm{~g}, 0.77 \mathrm{mmol})$ in THF $(20 \mathrm{~mL})$ at $-78^{\circ} \mathrm{C}$ in the dark. After $15 \mathrm{~min}$, the solution of ${ }^{t} \mathrm{BuMe} \mathrm{SiCl}_{2}$ $(0.116 \mathrm{~g}, 0.77 \mathrm{mmol})$ in THF $(10 \mathrm{~mL})$ was added dropwise at $0{ }^{\circ} \mathrm{C}$ and the resulting mixture was warmed up to room temperature for $45 \mathrm{~min} .{ }^{n} \mathrm{BuLi}(1.6 \mathrm{M}, 0.48 \mathrm{~mL}, 0.77 \mathrm{mmol})$ was added again at $0{ }^{\circ} \mathrm{C}$ to the pale yellow reaction mixture. After $15 \mathrm{~min}$ at room temperature, the solution was cooled to $-78{ }^{\circ} \mathrm{C}$ and $\mathbf{2}^{\prime}$ (0.100 g, $\left.0.29 \mathrm{mmol}\right)$ in THF $(10 \mathrm{~mL})$ was added dropwise. After addition, the mixture was warmed up to room temperature and the solution was stirred $1 \mathrm{~h}$ in the dark. The solvent was evaporated under reduced pressure and the residue was subjected to column chromatography on silica gel in the dark (hexane then hexane $\left./ \mathrm{CH}_{2} \mathrm{Cl}_{2}(9: 1, \mathrm{v} / \mathrm{v})\right)$ to give $\mathbf{2}$ as a pale yellow powder $\left(R_{\mathrm{f}}=0.34\right.$, hexane $\left./ \mathrm{CH}_{2} \mathrm{Cl}_{2}(9: 1, \mathrm{v} / \mathrm{v})\right)$. Yield: $78 \%, 0.200 \mathrm{~g}, 0.23 \mathrm{mmol} . \mathrm{mp}=203-204{ }^{\circ} \mathrm{C} .{ }^{1} \mathrm{H}$ NMR $\left(300 \mathrm{MHz}, \mathrm{CDCl}_{3}, 298 \mathrm{~K}\right): \delta 7.93(\mathrm{dd}, 2 \mathrm{H}, \mathrm{H}$ of naphthalene, $\left.{ }^{3} J_{\mathrm{HH}}=8.2 \mathrm{~Hz},{ }^{4} J_{\mathrm{HH}}=1.2 \mathrm{~Hz}\right), 7.92(\mathrm{~d}, 2 \mathrm{H}, \mathrm{C}(\mathrm{H})=\mathrm{P}$, $\left.{ }^{2} J_{\mathrm{PC}}=25.3 \mathrm{~Hz}\right), 7.53\left(\mathrm{t}, 2 \mathrm{H}, \mathrm{H}\right.$ of naphthalene, $\left.{ }^{3} J_{\mathrm{HH}}=7.6 \mathrm{~Hz}\right)$, $7.41\left(\mathrm{~s}, 4 \mathrm{H}, m-\mathrm{H}\right.$ of $\left.\mathrm{Mes}^{*}\right), 7.37$ (dd, $2 \mathrm{H}, \mathrm{H}$ of naphthalene, $\left.{ }^{3} J_{\mathrm{HH}}=7.1 \mathrm{~Hz},{ }^{4} J_{\mathrm{HH}}=1.2 \mathrm{~Hz}\right), 7.08\left(\mathrm{dd}, 4 \mathrm{H}, \mathrm{H}\right.$ of $\mathrm{C}_{6} \mathrm{H}_{4}$, $\left.{ }^{3} J_{\mathrm{HH}}=8.1 \mathrm{~Hz},{ }^{4} J_{\mathrm{HH}}=2.9 \mathrm{~Hz}\right), 6.79\left(\mathrm{~d}, 4 \mathrm{H}, \mathrm{H}\right.$ of $\left.\mathrm{C}_{6} \mathrm{H}_{4}\right), 1.49$ (s, 36H, o- $\left.{ }^{t} \mathrm{Bu}\right), 1.43\left(\mathrm{~s}, 18 \mathrm{H}, p-{ }^{t} \mathrm{Bu}\right) .{ }^{13} \mathrm{C}\left\{{ }^{1} \mathrm{H}\right\} \mathrm{NMR}(75.46 \mathrm{MHz}$, $\left.\mathrm{CDCl}_{3}, 298 \mathrm{~K}\right): \delta 175.99\left(\mathrm{~d}, \mathrm{C}(\mathrm{H})=\mathrm{P},{ }^{1} J_{\mathrm{P}-\mathrm{C}}=34.8 \mathrm{~Hz}\right), 153.96$ (s, o-Mes*(C)), 149.45 (s, $p$-Mes*(C)), $143.17\left(\mathrm{~d}, i-\mathrm{C}\right.$ of $\mathrm{C}_{6} \mathrm{H}_{4}$, $\left.{ }^{2} J_{\mathrm{PC}}=7.7 \mathrm{~Hz}\right), 140.57\left(\mathrm{~s}, \mathrm{C}_{\mathrm{q}}\right.$ of naphthalene), 139.31 (d, $i-\mathrm{C}$ of Mes*, $\left.{ }^{1} J_{\mathrm{PC}}=53.4 \mathrm{~Hz}\right), 138.05$ and $137.86\left(2 \mathrm{~s}, \mathrm{C}_{\mathrm{q}}\right.$ of naphthalene), $135.24\left(\mathrm{~s}, \mathrm{C}_{\mathrm{q}}\right.$ of $\left.\mathrm{C}_{6} \mathrm{H}_{4}\right), 130.43\left(\mathrm{~s}, m-\mathrm{C}\right.$ of $\left.\mathrm{C}_{6} \mathrm{H}_{4}\right), 128.32$ and 125.15 (2s, C's of naphthalene), 124.59 (d,o-C of $\mathrm{C}_{6} \mathrm{H}_{4},{ }^{3} J_{\mathrm{PC}}=$ $21.3 \mathrm{~Hz}$ ), 121.68 (s, $m-\mathrm{C}$ of Mes*), $38.24\left(\mathrm{~s}, o-C\left(\mathrm{CH}_{3}\right)_{3}\right), 35.03$ $\left(\mathrm{s}, m-C\left(\mathrm{CH}_{3}\right)_{3}\right), 33.88\left(\mathrm{~d}, o-\mathrm{C}\left(\mathrm{CH}_{3}\right)_{3},{ }^{4} J_{\mathrm{PC}}=6.4 \mathrm{~Hz}\right), 31.51$ $\left(\mathrm{s}, m-\mathrm{C}\left(\mathrm{CH}_{3}\right)_{3}\right) .{ }^{31} \mathrm{P}$ NMR $\left(121.5 \mathrm{MHz}, \mathrm{CDCl}_{3}, 298 \mathrm{~K}\right): \delta 256.23$ $\left(\mathrm{d}, \mathrm{C}(\mathrm{H})=\mathrm{P},{ }^{2} J_{\mathrm{PH}}=25.1 \mathrm{~Hz}\right)$. EI-MS: $m / z(\%) 305(20)[\mathrm{M}]^{+}$, $743(8)\left[\mathrm{M}-2^{t} \mathrm{Bu}\right]^{+}, 611$ (50) $\left[\mathrm{M}-\mathrm{Mes}^{*}\right]^{+}, 585$ (47) [M-PMes* $^{+}$, 308 (47) [M-2PMes*] ${ }^{+}$.

\subsection{Crystal structures}

5.3.1. Crystals data for 1 . Crystals suitable for X-ray diffraction were grown as yellow elongated plates by slow diffusion of $\mathrm{MeOH}$ into a chloroform solution of the compound at room temperature. Data were collected at $100 \mathrm{~K}$ using synchrotron X-ray radiation $(\lambda=0.70000 \AA)$ at the Swiss-Norwegian Beam Lines (SNBL), ESRF, Grenoble, France with a marresearch mar345 image plate detector. Formula: $\mathrm{C}_{64} \mathrm{H}_{76} \mathrm{P}_{2} ; M_{\mathrm{r}}=907.25 \mathrm{~g} \mathrm{~mol}^{-1}$; triclinic, space group $P \overline{1}, a=9.834(5), b=10.871(5), c=25.800(10) \AA$, $\alpha=88.42(2), \beta=83.77(2), \gamma=79.06(2)^{\circ}, V=2692(2) \AA^{3}$; $\mathrm{Z}=2 ; D_{x}=1.119 \mathrm{~g} \mathrm{~cm}^{-3}, \mu=0.12 \mathrm{~mm}^{-1} ; F(000)=980$. Crystal dimensions: $0.20 \times 0.05 \times 0.05 .8700$ independent 
reflections, 6992 with $I>2 \sigma(I)$. Goodness-of-fit on $F^{2}=$ $1.1263 ; R(I)>2 \sigma(I)=0.066 ; w \mathrm{R} 2=0.094,595$ parameters; maximum/minimum residual density $0.52 /-0.72$ e $\AA^{-3}$. The crystal structure was solved with SIR $2004^{24}$ and refined with CRYSTALS $^{25}$ by full matrix least-squares using anisotropic thermal displacement parameters for all non-hydrogen atoms. Hydrogen atoms were included with a riding model. CCDC reference number: 815021 .

5.3.2. Crystals data for 2 . Single colourless crystals were obtained by slow diffusion of $\mathrm{MeOH}$ into a chloroform solution of the compound at room temperature: crystal dimensions $0.70 \times 0.50 \times 0.30 \mathrm{~mm}, \mathrm{C}_{60} \mathrm{H}_{74} \mathrm{P}_{2}, M=857.20 \mathrm{~g} \mathrm{~mol}^{-1}$, monoclinic, space group $P 12_{1} / n 1, \quad a=10.185(10)$, $b=17.940(5), c=29.06(2) \AA, \alpha=\gamma=90, \beta=96.79(5)^{\circ}$, $V=5272(7) \AA^{3}, Z=4, D_{x}=1.080 \mathrm{~g} \mathrm{~cm}^{-3}, \mu=0.12 \mathrm{~mm}^{-1}$, $F(0000)=1856$. Data were collected at $293 \mathrm{~K}$ on a STOE IPDS 2 diffractometer using a Mo $K \alpha$ X-ray source $(\lambda=0.71073 \AA)$ and a graphite monochromator. 10372 reflections collected with $5<\theta<29^{\circ}, 7342$ with $I>2 \sigma(I)$. Data were integrated using the program XDS. ${ }^{26}$ The structure was solved by the chargeflipping method using Superflip ${ }^{27}$ and refined anisotropically on $F^{2}$ using the CRYSTALS package. ${ }^{25}$ Hydrogen atoms were included with a riding model. One ${ }^{t} \mathrm{Bu}$ group is disordered over two positions. Final results: $R(I>2 \sigma(I))=0.050$, $w \mathrm{R} 2=0.081$, goodness-of-fit on $F^{2}=0.9830,587$ parameters, maximum/minimum residual density $0.29 /-0.32$ e $\AA^{-3}$. CCDC reference number: 815022 .

\subsection{Electrochemistry and EPR measurements}

Cyclic voltammetry measurements were performed on a BAS-CV-50W analyzer with a homebuilt one-compartment cell using a $\mathrm{Pt}$ working electrode $(1 \mathrm{~mm} \varnothing)$, a Pt counter electrode and a $\mathrm{Ag} / \mathrm{AgNO}_{3}$ reference electrode. The experiments were carried out in dry THF using a concentration of approximately $10^{-3} \mathrm{M}$ of the corresponding compound and $0.1 \mathrm{M}$ tetrabutylammonium hexafluorophosphate $\left(\mathrm{TBAPF}_{6}\right)$ as a supporting electrolyte. Ferrocene was used as an internal reference.

EPR spectra were recorded on a Bruker ESP-300 spectrometer (100 KHz field modulation) equipped with a B-VT 2000 variable temperature controller. Samples were prepared in a glovebox using freshly degassed THF (three successive "FreezePump-Thaw" cycles). Solutions of $\mathrm{Na}$ naphthalenide in THF were used for chemical reductions. Electrochemical reductions were carried out by electrolysis in situ in the EPR cavity using a two-Pt electrodes cell together with a Princeton Applied Research (Model 362) potentiostat. $\operatorname{TBAPF}_{6}(0.1 \mathrm{M})$ was used as a supporting electrolyte. Electrochemical reductions at a controlled potential were performed by using a home made EPR quartz cell made up of a Pt working electrode, a Pt counter electrode and an Ag wire as a pseudo-reference.

\subsection{Computational methods}

Geometries of the six rotamers of the radical anion $\mathbf{A}^{\bullet-}$ were optimized with the Turbomole program ${ }^{28}$ using the B-P86 functional and the $\mathrm{SV}(\mathrm{P})$ standard basis set. Minima were characterized with harmonic frequency calculations (all frequencies real). The hyperfine coupling constants were calculated with the Gaussian03 package ${ }^{29}$ using the B3LYP functional $^{30}$ and the $6-31+\mathrm{G}^{*}$ basis set.

\section{Acknowledgements}

The authors thank the Swiss National Science Foundation for financial support.

\section{References}

1 (a) Y.-W. Zhong, N. Villa, J. C. Henderson and H. D. Abruna, Inorg. Chem., 2009, 48, 991; (b) W. R. Browne and B. L. Feringa, Chimia, 2010, 64, 398; (c) G. Chen, I. Mahmud, L. N. Dawe, L. M. Daniels and Y. Zhao, J. Org. Chem., 2011, 76, 2701; (d) J. Areephong, H. Logtenberg, W. R. Browne and B. L. Feringa, Org. Lett., 2010, 12, 2132.

2 (a) A. Trabolsi, M. Hmadeh, N. M. Khashab, D. C. Friedman, M. E. Belowich, N. Humbert, M. Elhabiri, H. A. Khatib, A.-M. Albrecht-Gary and J. F. Stoddart, New J. Chem., 2009, 33, 254; (b) Q. Zhang, Y. Tu, H. Tian, Y.-L. Zhao, J. F. Stoddart and H. Agren, J. Phys. Chem. B, 2010, 114, 6561; (c) S. Durot, F. Reviriego and J.-P. Sauvage, Dalton Trans., 2010, 39, 10557.

3 (a) E. Beer, J. Daub, C. Palivan and G. Gescheidt, J. Chem. Soc., Perkin Trans. 2, 2002, 1605; (b) A. W. Misiolek, A. S. Ichimura, R. A. Gentner, R. H. Huang, V. P. McCaffrey and J. E. Jackson, Inorg. Chem., 2009, 48, 9005.

4 K. Nikitin, E. Lestini, J. K. Stolarczyk, H. Müller-Bunz and D. Fitzmaurice, Chem.-Eur. J., 2008, 14, 1117.

5 (a) F. Riobé, N. Avarvari, P. Grosshans, H. Sidorenkova, T. Berclaz and M. Geoffroy, Phys. Chem. Chem. Phys., 2010, 12, 9650; (b) I. Danila, F. Biaso, H. Sidornkova, M. Geoffroy, M. Fourmigué, E. Levillain and N. Avarvari, Organometallics, 2009, 28, 3691; (c) M. Iyoda, M. Hasegawa and Y. Miyake, Chem. Rev., 2004, 104, 5085; (d) F. Riobé, P. Grosshans, H. Sidorenkova, M. Geoffroy and N. Avarvari, Chem.-Eur. J., 2009, 15, 380.

6 (a) D. Jacquemin, E. A. Perpète, F. Maurel and A. Perrier, J. Phys. Chem. Lett., 2010, 1, 434; (b) D. Jacquemin, C. Michaux, E. A. Perpète, F. Maurel and A. Perrier, Chem. Phys. Lett., 2010, 488, 193.

7 (a) J. Areephong, J. H. Hurenkamp, M. T. W. Milder, A. Meetsma, J. L. Herek, W. R. Browne and B. L. Feringa, Org. Lett., 2009, 11, 721; (b) A. Staykov, J. Areephong, W. R. Browne, B. L. Feringa and K. Yoshizawa, ACS Nano, 2011, 5, 1165.

8 (a) M. Geoffroy, A. Jouaiti, G. Terron, M. Cattani-Lorente and Y. Ellinger, J. Phys. Chem., 1992, 96, 8241; (b) M. Washington, J. L. Payton, M. C. Simpson and J. D. Protasiewicz, Organometallics, 2011, 30, 1975; (c) V. B. Gudimetla, L. Ma, M. P. Washington, J. L. Payton, M. C. Simpson and J. Protasiewicz, Eur. J. Inorg. Chem., 2010, 854.

9 C. Dutan, S. Shah, R. C. Smith, S. Choua, T. Berclaz, M. Geoffroy and J. D. Protasiewicz, Inorg. Chem., 2003, 42, 6241.

10 A. Al Badri, A. Jouaiti and M. Geoffroy, Magn. Reson. Chem., 1999, 37, 735 .

11 (a) A. O. King, N. Okukado and E. Negishi, Chem. Commun., 1977, 683; (b) R. Jana, T. P. Pathak and M. S. Sigman, Chem. Rev., 2011, 111, 1417; (c) E. Negishi, Q. Hu, Z. Huang, G. Wang and N. Yin, The Chemistry of Organozinc Compounds, ed. Z. Rappoport and I. Marek, John Wiley \& Sons Ltd., Chichester, England, 2006, ch. 11, p. 457; (d) E. Negishi, Bull. Chem. Soc. Jpn., 2007, 80, 233

12 M. Yoshifuji, I. Shima and N. Inamoto, J. Am. Chem. Soc., 1981, 103, 4587.

13 H. Kawanami, K. Toyota and M. Yoshifuji, J. Organomet. Chem., 1997, 535, 1

14 (a) N. Miyaura and A. Suzuki, Chem. Rev., 1979, 95, 2457; (b) A. Suzuki, Angew. Chem., Int. Ed., 2011, 50, 2; (c) J. Hassan, M. Sévignon, C. Gozzi, E. Schultz and M. Lemaire, Chem. Rev., $2002,102,1359$.

15 R. Appel, J. Menzel, F. Knoch and P. Volz, Z. Anorg. Allg. Chem., 1986, 534, 100.

16 M. Chentit, H. Sidorenkova, M. Geoffroy and Y. Ellinger, J. Phys. Chem. A, 1998, 102, 10469. 
17 L. Cataldo, S. Choua, T. Berclaz, M. Geoffroy, N. Mézailles, L. Ricard, F. Mathey and P. Le Floch, J. Am. Chem. Soc., 2001, 123, 6654; S. Choua, C. Dutan, L. Cataldo, T. Berclaz, M. Geoffroy, N. Mézailles, A. Moores, L. Ricard and P. Le Floch, Chem.-Eur. J., 2004, 10, 4080.

18 G. R. Hanson, K. E. Gates, C. Noble, M. Griffin, A. Mitchell and S. Benson, J. Inorg. Biochem., 2004, 98, 903. XSophe-eprview. A computer simulation software suite for the analysis of EPR spectra. Bruker BioSpin Karlsruhe, Germany.

19 F. Tellier, R. Sauvêtre and J.-F. Normant, J. Organomet. Chem., 1985, 292, 19.

20 L. Sabater, R. Guillot and A. Aukauloo, Tetrahedron Lett., 2005, 46, 2923.

21 L. Goichi, K. Segawa, S. Suzuki and S. Toyota, Synthesis, 2005, 13, 2116.

22 F. Voegtle, H. Koch and K. Rissanen, Chem. Ber., 1992, 125, 2129.

23 S. L. Goodman, G. Höltzeman, G. A. G. Sulyok and H. Kessler, J. Med. Chem., 2002, 45, 1045.

24 M. C. Burla, R. Caliandro, M. Camalli, B. Carrozzini, G. L. Cascarano, L. Caro, C. Giacovazzo, G. Polidori and R. J. Spagna, J. Appl. Crystallogr., 2005, 38, 381.

25 P. W. Betteridge, J. R. Carruthers, R. I. Cooper, K. Prout and D. J. Watkin, J. Appl. Crystallogr., 2003, 36, 1487.

26 W. Kabsch, J. Appl. Crystallogr., 1993, 26, 795.
27 L. Palatinus and G. Chapuis, J. Appl. Crystallogr., 2007, 40, 786.

28 R. Ahlrichs, M. Bär, M. Häser, H. Horn and C. Kölmel, Chem. Phys. Lett., 1989, 162, 165.

29 M. J. Frisch, G. W. Trucks, H. B. Schlegel, G. E. Scuseria, M. A. Robb, J. R. Cheeseman, J. A. Montgomery, Jr., T. Vreven, K. N. Kudin, J. C. Burant, J. M. Millam, S. S. Iyengar, J. Tomasi,V. Barone, B. Mennucci, M. Cossi, G. Scalmani, N. Rega, G. A. Petersson, H. Nakatsuji, M. Hada, M. Ehara, K. Toyota, R. Fukuda, J. Hasegawa, M. Ishida, T. Nakajima, Y. Honda, O. Kitao, H. Nakai, M. Klene, X. Li, J. E. Knox, H. P. Hratchian, J. B. Cross, C. Adamo, J. Jaramillo, R. Gomperts, R. E. Stratmann, O. Yazyev, A. J. Austin, R. Cammi, C. Pomelli, J. W. Ochterski, P. Y. Ayala, K. Morokuma, G. A. Voth, P. Salvador, J. J. Dannenberg, V. G. Zakrzewski, S. Dapprich, A. D. Daniels, M. C. Strain, O. Farkas, D. K. Malick, A. D. Rabuck, K. Raghavachari, J. B. Foresman, J. V. Ortiz, Q. Cui, A. G. Baboul, S. Clifford, J. Cioslowski, B. B. Stefanov, G. Liu, A. Liashenko, P. Piskorz, I. Komaromi, R. L. Martin, D. J. Fox, T. Keith, M. A. Al-Laham, C. Y. Peng, A. Nanayakkara, M. Challacombe, P. M. W. Gill, B. Johnson, W. Chen, M. W. Wong, C. Gonzalez and J. A. Pople, Gaussian 03, Revision B.03, Gaussian, Inc., Pittsburgh, PA, 2003.

30 (a) A. D. Becke, J. Chem. Phys., 1993, 98, 6548; (b) C. Lee, W. Yang and R. G. Parr, Phys. Rev. B, 1988, 37, 785. 